\title{
Intrapleural Fibrinolytics- A review
}

\author{
Dr. Girish.L.Dandagi.MBBS, MD*. \\ *Associate Professor, Department of TB and Respiratory Medicine, Belgaum Institute of medical sciences, \\ Belgaum, Karnataka, INDIA.
}

\begin{abstract}
Fibrinolytic therapy can be used for complicated pleural effusions or empyema without the need for operative intervention. Intrapleural administration of Fibrinolytics prevents intrapleural organization and loculation. However, the success of this therapy has provided a strong rationale for the continued utilization of fibrinolytic therapy to address extensive intrapleural loculation and lung entrapment. Over the last several years; additional studies were done to explore the efficacy and safety of intrapleurally administered Fibrinolytics.

Key words: Streptokinase, urokinase, empyema, Fibrinolytics
\end{abstract}

\section{Introduction}

The fibrin strands within pleural exudates initiate intrapleural loculation in the form of fibrin. The clearance of this fibrin by intrapleural administration of Fibrinolytics prevents intrapleural organization and loculation. Beginning in the 1940s, Dr Sherry ${ }^{1}$ and Tillett et al $^{2}$ demonstrated that preparations of streptokinase or streptodornase could be used to resolve pleural loculations attributable to parapneumonic effusions or hemothoraxes ${ }^{3}$. However, the success of this therapy has provided a strong rationale for the continued utilization of fibrinolytic therapy to address extensive intrapleural loculation and lung entrapment .Over the last several years; additional studies were done to explore the efficacy and safety of intrapleurally administered Fibrinolytics. The current article reviews about these intraplueral agents in detail.

\section{Discussion}

Various agents used as Fibrinolytics like streptokinase urokinase and others are discussed below in detail. Streptokinase has been associated with febrile reactions but has been generally well tolerated, as reported in a number of studies. Intrapleural streptokinase, as commonly used for intrapleural administration, does not induce systemic fibrinolysis and is relatively free of hemorrhagic risk ${ }^{4,5}$.

Intrapleural urokinase has likewise been reported to be well-tolerated ${ }^{6}$. The cost of intrapleurally administered agents has favored streptokinase as reported in prior studies, but urokinase has been reported to be cost effective. Streptokinase is available in a 750,000 IU dose and 15 lakh IU dose. Urokinase is now available in 250,000 IU / 5,000,000 I.U. / 7,50,000 I.U. / 10,00,000 I.U dose. Tissue plasminogen activator (tPA ) is available in $50-\mathrm{mg}$ vials ${ }^{7}$.

\section{Fibrinolytic Agents Used for Intrapleural Applications.}

1. Streptokinase: Single-chain glycoprotein of molecular weight 40,000-50,000 kDa. Not an enzyme which generates plasmin through complex formation with and catalysis of plasminogen. Rapid half-life; cleared within minutes. It can induce antistreptokinase antibodies and a least expensive fibrinolysin ${ }^{8}$.

2. Urokinase plasminogen activator (uPA): Low-molecular-weight form which predominates in commercial preparations; molecular weight 33,000 $\mathrm{kDa}$. Rapid plasma half-life; cleared within minutes.Directly activates plasminogen to form plasmin. Endogenous plasminogen activator that can be detected in pleural fluids and plasma.

3. Tissue plasminogen activator (tPA): Glycosylated protein of molecular weight $68,000 \mathrm{kDa}$. Rapid plasma half-life; cleared within minutes. Recombinant material is used therapeutically. Endogenous tPA detectable in pleural fluid and plasma ${ }^{8}$.

\section{Overview of Clinical Trials of Intrapleural Fibrinolytic Therapy}

In the 1970s, Bergh and colleagues ${ }^{3}$ revisited the use of streptokinase as an intervention to treat loculations associated with hemothoraxes or parapneumonic effusions. In this study thirty-eight patients with haemothorax or empyema, in whom conventional drainage treatment had proved ineffective were treated with streptokinase instillations. An increased yield of fluid was noted in all 30 of 38 cases, up to $1300 \mathrm{ml}$ after one instillation. Re-expansion of the lung was observed radiologically in 30 cases. No serious complications occurred with streptokinase instillation. 
Bouros and colleagues ${ }^{9}$ likewise found that urokinase was similarly well tolerated and effective after intrapleural instillation in patients in whom adequate drainage was not achieved with a single chest tube placed for complicated Para pneumonic effusions or empyema's. Clinical and radiologic improvement was noted in 19 of 20 patients, with an "excellent" radiologic response in 13 patients. In a follow-up uncontrolled trial, 50 patients with para pneumonic effusions or empyema and inadequate chest tube drainage were randomized, in a double-blind manner, to receive either urokinase or streptokinase by the same group. They found that streptokinase-treated patients were more prone to the development of febrile reactions, and that both agents appeared to decrease the need for surgical intervention ${ }^{10}$ In this trial, the fibrinolytics were given in $100 \mathrm{~mL}$ of normal saline, and a dwell time of 3 hours was used. The daily dose of streptokinase was 2,50,000 IU/dose, while that of uPA was 1,00,000 IU/dose, which are comparable to those used in other clinical trials. This group reported that only about $10 \%$ of patients failed to respond to administration of fibrinolytic agents over a 5 -year period, but in such cases, video-assisted thoracoscopy was an effective follow-up option ${ }^{11}$.

In a multicenter, uncontrolled trial of 48 patients from Mexico, including those with empyema and hemothorax, intrapleural streptokinase was found to be effective in $92 \%$ of patients and obviated the need for surgical intervention ${ }^{12}$.In this study forty-eight patients were studied; there were 30 patients with empyemas, 14 with hemothorax, and 4 patients with malignant pleural effusions without lung trapping. Successful fibrinolysis was obtained in 44 patients, with complete resolution of the pleural collection and adequate radiologic and spirometric improvement. In three of four patients with multiloculated malignant hemothorax with high-yielding pleural drainage, Intrapleural Streptokinase treament allowed successful lysis of loci and an adequate pleurodesis was achieved. Only four patients required surgical treatment.

The findings in a report from Estonia were likewise encouraging, in that ${ }^{13} 28$ patients (aged 22 to 62 years) with multi loculated pleural effusions were treated with intrapleural instillations of streptokinase after unsuccessful conventional chest tube drainage. Twenty-three pleural effusions were grossly purulent, others were loculated effusions with low $\mathrm{pH}$. Treatment with streptokinase was started most commonly one day after chest tube placement. Once a day after clamping the chest tube streptokinase was administered intrapleurally for $10-15$ minutes as a solution of 250,000 units in $100 \mathrm{ml}$ normal saline. The tube remained clamped for 3 hours. Eleven patients experienced some adverse effects of streptokinase therapy, most frequently chest pain and elevation of body temperature in one case pleural effusion became hemorrhagic, and one patient had nasal bleeding

In a study from a Veterans Administration hospital in the United States, favorable results were likewise observed in 18 of 26 patients treated with either streptokinase or urokinase for empyema, and the treatment was felt to again obviate the need for surgical intervention ${ }^{14}$. Twenty-six patients were treated. Sixty-two percent (16/26) had complete resolution (CR) of symptoms, near or complete normalization of chest radiographic findings, and required no surgery or empyema tubes. Bleeding occurred in a single patient (4\%). There was no mortality associated with fibrinolytic use. Similar results were reported in a study of 54 patients with empyema's or hemothoraxes treated with intracavitary, trans catheter urokinase ${ }^{15}$.

In pediatric patients, intrapleural urokinase was likewise found to be effective in all 9 children age 6 or less with intrapleural loculations associated with complicated parapneumonic effusions ${ }^{16}$. In the aggregate, the results of several uncontrolled trials support the use of fibrinolytic therapy for intrapleural loculations. In this study nine children, ages 6 months to 6 years, with complicated parapneumonic effusions who received intrapleural urokinase after failing to respond to IV antibiotics and closed-tube thoracostomy drainage. Four subjects had additional thoroscopic adhesiolysis before intrapleural instillation of urokinase; 20,000 IU of diluted urokinase was instilled three times a day via the thoracostomy tube for 3 days. Among these eight subjects responded to 3 days of urokinase instillation, with increased thoracostomy tube drainage and clinical resolution of symptoms. The remaining subject responded to a second course of instillation. All subjects tolerated the procedure well. No bleeding, fever, anaphylaxis, or allergic reactions were noted. The coagulation parameters remained unchanged.

There are relatively few randomized, controlled clinical trials that address the use of intrapleural fibrinolytics to relieve intrapleural loculations. In one such trial, Davies and colleagues ${ }^{17}$ found that streptokinase facilitated pleural drainage and radiographic improvement of the intrapleural collections, which were due to empyema. In this trial, 24 patients were randomized and received either intrapleural saline or streptokinase daily over 3 days. Only patients in the control group required surgical intervention, and systemic fibrinolysis or bleeding did not occur in the streptokinase treated patients.

In another controlled trial of 31 consecutive patients with multiloculated effusions, urokinase instillation was found to be superior to saline administration ${ }^{18}$. Patients again received a course of treatment over 3 days. Clinical and radiographic improvement was seen in 13 of 15 patients treated with urokinase and only 4 of 16 in the saline-treated patients. Twelve patients in the control group were subsequently treated with uPA, and half of them then had resolution of intrapleural loculations. The authors concluded that intrapleural administration of uPA was effective in the treatment of multiloculated effusions. 
These results were confirmed in another controlled clinical trial from Turkey ${ }^{19}$.In this study, Forty-nine patients with Para pneumonic empyema were randomly assigned to receive either intrapleural urokinase or normal saline treatment. The daily volume instilled through a chest tube was $100 \mathrm{ml}$ in both groups. Urokinase $(100,000$ IU/day) was diluted in normal saline before instillation. The mean volume of drained fluid during the five-day treatment period was significantly greater in the urokinase group than in the control group. The subsequent decortication rate was $60 \%$ and $29.1 \%$, respectively. The duration of hospitalization was also shorter in the urokinase group than in the saline group.

It has been observed by Dourous ${ }^{20}$ that intrapleural fibrinolytic at a daily dose of 1,00,00 IU for 3 days is safe and effective in improving chest-tube drainage and reducing the hospital stay of patients with empyema. This study showed that patients who received intrapleural fibrinolytics had a decreased need for hospitalization compared with patients who received saline intrapleurally. Also it was observed that intrapleural fibrinolytic treatment does not appear to alter systemic coagulation parameters. In fact, no clinical or stastically significant deviations of the hematologic parameters were observed.s

\section{Conclusion}

It can be concluded that routinely fibrinolytic therapy can be used for complicated pleural effusions or empyema without the need for operative intervention.

\section{Reference:}

[1] Tillett WS, Sherry S: The effect in patients with streptococcal fibrinolysis (streptokinase) and streptococcal desoxyribonuclease on fibrinous, purulent, and sanguinous pleural exudations. J Clin Invest 1949, 28:173-190.

[2] Tillett WS, Sherry S, Read CT. The use of streptokinase-streptodornase in the treatment of postpneumonic empyema.J Thorac Surg $1951 ; 21: 275-297$

[3] Bergh NP, Ekroth R, Larsson S, Nagy P: Intrapleural streptokinase in the treatment of haemothorax and empyema. Scand J Cardiovasc Surg 1977, 11:265-268.

[4] Davies CW Shelok H,,and Davies R J O.The systemic fibrinolytic activity of intrapleural streptokinase Am J Resir Crit Care Med 1998; $157: 328-330$

[5] Cameron R. Intra-pleural fibrinolytic therapy vs. conservative management in the treatment of parapneumonic effusions and empyema. Cochrane Database Syst Rev. 2000;(3):CD002312.

[6] Sahn SA. Use of fibrinolytic agents in the management of complicated parapneumonic effusions and empyemas. Thorax. 1998;53(suppl 2): S65-S72.

[7] Walker CA, Shirk MB, Tschampel MM . Intrapleural alteplase in a patient with complicated pleural effusion. Ann Pharmacother. 2003;37:376-379.

[8] Bell WR. Present day thrombolytic therapeutic agents:pharmocotherapeutics and pharmocodynamics. Rev Cardiovasc Med. 2002;2(suppl 2): S24-44.

[9] Bouros D, Schiza S, Tzanakis N, J. Drositis, N. Siafakas. Intrapleural urokinase in the treatment of complicated parapneumonic pleural effusions and empyema. Eur Respir J. 1996;9:1656 -1659

[10] Bouros D, Schiza S, Patsourakis G, Chalkiadakis G, Panagou P, Siafakas NM. Intrapleural streptokinase versus urokinase in the treatment of complicated parapneumonic effusions: a prospective, double-blind study. Am J Respir Crit Care Med. 1997;155:291295.

[11] Bouros D, Antoniou KM, Chalkiadakis G, Drositis J, Petrakis I, Siafakas N.. The role of video assisted thoracoscopic surgery in the treatment of parapneumonic empyema after the failure of fibrinolytics. Surg Endosc. 2002;16:151-154.

[12] Jerjes-Sánchez C, Ramirez-Rivera A, Elizalde JJ, Delgado R, Cicero R, Ibarra-Perez C, Intrapleural fibrinolysis with streptokinase as an adjunctive treatment in hemothorax and empyema: a multicenter trial. Chest.1996;109:1514-1519

[13] Laisaar T, Puttsepp E, Laisaar V. Early administration of intrapleural streptokinase in the treatment of multiloculated pleural effusions and pleural empyemas. Thorac Cardiovasc Surg. 1996;44:252-256.

[14] Temes RT., Follis F., Kessler RM., Pett SB., Wernly JA. Intrapleural fibrinolytics in management of empyema thoracis. Chest. 1996;110:102-106.

[15] Basile A, Boullosa-Seoane E, Dominguez VL. Intrapleural fibrinolysis in the management of empyemas and haemothoraces: our experience. Radiol Med (Torino). 2003;105:12-16.

[16] Krishnan S, Amin N, Dozor AJ, Stringel G. Urokinase in the management of complicated parapneumonic effusions in children. Chest. 1997;112: 1579-1583.

[17] Davies RJ, Traill ZC, Gleeson FV. Randomised controlled trial of intrapleural streptokinase in community acquired pleural infection.Thorax. 1997;52:416-421.

[18] Bouros D, Schiza S, Tzanakis N, Chalkiadakis G, Drositis J, Siafakas N. Intrapleural urokinase versus normal saline in the treatment of complicated parapneumonic effusions and empyema: a randomized, double-blind study. Am J Respir Crit Care Med. 1999;159:37-42.

[19] Tuncozgur B, Ustunsoy H, Sivrikoz MC, Dikensoy O, Topal M, Sanli M. Intrapleural urokinase in the management of parapneumonic empyema: a randomised controlled trial. Int J Clin Pract. 2001;55:658-660.

[20] Dourous B, Sophia S, Tzankis N, George C, John D, Nikolaos S :.Intrapleural urokinase versus normal saline in the treatment of complicated parapneumonic effusions and empyema. Am J Respir care Med 1999;159:37-42

[21] Thomson AH, Hull J, Kumar MR , Wallis C, Balfour Lynn IM. Randomised trail of intrapleural urokinase in the treatment of childhood empyema..Thorax 2002;57:343-347

[22] Diacon AH, Johan T, Mace MS, Bernard W, Van de Wal, and Chris TB.Intrapleural streptokinase for empyema and complicated parapneumonic Effusions Am J Respir Crit Care Med 2004;170:49-53

[23] Yasuharu T,Matsushima D,Stein GH , and Miyagi S.Intrapleural fibrinolytic agents for empyema and complicated parapneumonic effusion Chest 2006;129;783-790.

[24] Maskel NA.;Davies,Christopher WH; Nunn ,Andrew J, Hedley EL: et al. Controlled trail of intrapleural streptokinase for pleural infection N Engl J Med 2005;352:865-74 
[25] Davies CW Shelok H,,and Davies R J O.The systemic fibrinolytic activity of intrapleural streptokinase Am J Resir Crit Care Med 1998;157:328-330

[26] Acharya PR , Kusum V. Shah Empyema thoracis: A clinical study.Ann. Thorac Med - 2007;2:14-17

[27] Simpson G, Roomes D, Reeves B: Successful treatment of empyema thoracis with human recombinant deoxyribonuclease. Thorax 2003;58:365-366.

[28] Menéndez-González, Manuel, Oliva-Nacarino, Pedro; Álvarez-Cofiño, Almudena. Cerebral gas embolism caused by pleural fibrinolytic treatment. Stroke : 2007; 38:2602-2604.

[29] Dionne AS, Edmund JR, Scott AS, Jeffrey EA, Parker LA., and Preston B R. Intrapleural tissue plasminogen activator for complicated pleural effusions.J Trauma 2004;57:1178 -1183.

[30] Cameron R. Intra-pleural fibrinolytic therapy vs. conservative management in the treatment of parapneumonic effusions and empyema. Cochrane Database Syst Rev. 2000;(3):CD002312. 